\title{
microRNA-361 targets Wilms' tumor 1 to inhibit the growth, migration and invasion of non-small-cell lung cancer cells
}

\author{
SHUXIANG YANG $^{1 *}$, YINGCHAO ZHANG $^{2 *}$, XIN ZHAO $^{3}$, JINGZHENG WANG $^{4}$ and JIANJING SHANG ${ }^{4}$ \\ ${ }^{1}$ Department of General Internal Medicine, Tianjin Hospital, Tianjin 300211; Departments of ${ }^{2}$ Respiration and \\ ${ }^{3}$ General Surgery, Tianjin Baodi Hospital, Tianjin 301800; ${ }^{4}$ Department of Clinical Laboratory, \\ Dongping People's Hospital, Tai'an, Shandong 271500, P.R. China
}

Received October 15, 2015; Accepted September 2, 2016

DOI: $10.3892 / \mathrm{mmr} .2016 .5858$

\begin{abstract}
The expression and functions of microRNA-361 (miR-361) have been studied in various human cancers. However, its expression and role in non-small-cell lung cancer (NSCLC) remains unclear. In the present study, the expression levels of miR-361 in NSCLC tissues and cell lines were determined using reverse transcription-quantitative polymerase chain reaction (RT-qPCR). In addition, the effect of miR-361 on the proliferation, migration and invasion of NSCLC cells was assessed.Furthermore, a dual-Luciferase reporter assay, RT-qPCR and western blotting were performed to investigate whether miR-361 directly targeted the $3^{\prime}$ untranslated region of Wilms' tumor 1 (WT1). The results of the present study revealed that miR-361 was downregulated in NSCLC tissues and cell lines. Enforced expression of miR-361 suppressed the proliferation, migration and invasion of NSCLC cells. WT1 was identified as a direct target gene of miR-361 in NSCLC. Furthermore, knockdown of WT1 had similar effects to miR-361 overexpression in NSCLC cells. The present study provided novel insights into the molecular mechanism underlying the rapid growth and metastasis of NSCLC, and identified the association between miR-361 and WT1 as a potential therapeutic target for the treatment of NSCLC.
\end{abstract}

\section{Introduction}

Lung cancer is the leading cause of cancer-associated mortality in men and women, and its incidence is increasing worldwide $(1,2)$. It was estimated that there would be 221,200 new cases of lung cancer, and 158,040 patients would succumb to the disease, in the USA in 2015 (3). Based on histology,

Correspondence to: Professor Yingchao Zhang, Department of Respiration, Tianjin Baodi Hospital, 8 Guangchuan Road, Tianjin 301800, P.R. China

E-mail: yingchaozhang@yeah.net

*Contributed equally

Key words: non-small-cell lung cancer, microRNA-361, Wilms' tumor 1 lung cancer may be classified into small-cell lung cancer and non-small-cell lung cancer (NSCLC) (4). NSCLC, which is responsible for $>85 \%$ of lung cancer cases, includes squamous cell carcinoma, adenocarcinoma, bronchioloalveolar carcinoma and large-cell carcinoma (5). Currently, the primary therapeutic treatments for NSCLC are comprehensive, including surgical resection, chemotherapy and radiotherapy (6). Despite advances in treatment, the 5-year survival rate for NSCLC has remained at $15-20 \%$, with a median survival of 8-12 months (7). The majority of NSCLC patients are diagnosed at a late or advanced stage of the disease, when their tumors and metastatic lesions have become intractable to current standard therapies (8). It is therefore necessary to elucidate the underlying molecular mechanisms that regulate NSCLC growth and metastasis, and investigate novel therapeutic strategies for patients with NSCLC.

Numerous studies have demonstrated that microRNAs (miRNAs) contribute to carcinogenesis, development and metastasis in various human cancers (9-11). miRNAs are non-coding, endogenous, single-stranded RNA molecules of 19-22 nucleotides in length (12). miRNAs negatively regulate the expression of target messenger RNAs (mRNAs) through binding to the $3^{\prime}$ untranslated region (UTR) of target mRNAs in a complementary base-pairing manner, resulting in translational repression or mRNA degradation (13). miRNAs are involved in a number of physiological and pathological processes, including cell proliferation, differentiation, morphogenesis, cell cycle progression, apoptosis, metastasis, and glucose and lipid metabolism (14-16). It is now well established that miRNAs may act as oncogenes or tumor suppressors in the initiation and progression of human cancers, depending on their target mRNAs $(17,18)$. These studies indicated that miRNAs are important regulators of tumorigenesis and may be investigated as potential targeted therapy for the treatment of cancers.

miR-361 has been studied in multiple human cancers. However, the role of miR-361 in NSCLC is still unclear. The objective of the present study was, therefore, to elucidate the expression and biological roles of miR-361 in NSCLC, and to investigate its underlying molecular mechanisms.

\section{Materials and methods}

Patients and clinical specimens. The present study was approved by the Ethics Committee of Tianjin Baodi Hospital 
(Tianjin, China), and written informed consent was obtained from all subjects. NSCLC tissue and matched normal adjacent tissue (NAT) samples were obtained from 34 NSCLC patients who underwent surgery resection at Tianjin Hospital. None of the patients received any therapeutic treatment prior to participation in the present study. Tissues were immediately snap-frozen in liquid nitrogen and stored at $-80^{\circ} \mathrm{C}$ until analysis.

Cell culture and transfection. $\mathrm{H} 23$ and A549 human NSCLC cell lines, BEAS-2B human non-tumorigenic bronchial epithelial cells and HEK293T human embryonic kidney cells were purchased from the Chinese Academy of Sciences (Shanghai, China). BEAS-2B cells were maintained in LHC-9 medium (Gibco; Thermo Fisher Scientific, Inc., Waltham, MA, USA) supplemented with $10 \%$ fetal bovine serum (FBS; Gibco; Thermo Fisher Scientific, Inc.). H23, A549 and HEK293T cells were cultured in RPMI-1640 medium (Gibco; Thermo Fisher Scientific, Inc.) containing 10\% FBS, $100 \mathrm{U} / \mathrm{ml}$ penicillin (Gibco; Thermo Fisher Scientific, Inc.) and $100 \mathrm{mg} / \mathrm{ml}$ streptomycin (Gibco; Thermo Fisher Scientific, Inc.). All cell lines were incubated in a humidified $5 \% \mathrm{CO}_{2}$ cell incubator at $37^{\circ} \mathrm{C}$.

miR-361 mimic, negative control (NC) and the luciferase reporter plasmids, PGL3-WT1-3'UTR wild-type (Wt) and PGL3-WT1-3'UTR mutant (Mut), were purchased from GeneChem Co., Ltd. (Shanghai, China). WT1 small interfering (si)RNA and control siRNA were obtained from Guangzhou RiboBio Co., Ltd. (Guangzhou, China). Cell transfection and cotransfection assays were performed using Lipofectamine ${ }^{\circledR} 2000$ (Invitrogen; Thermo Fisher Scientific, Inc.) according to the manufacturer's protocol.

RNA isolation and reverse transcription-quantitative polymerase chain reaction ( $R T-q P C R)$. Total RNA was extracted from tissues and cells using TRIzol ${ }^{\circledR}$ reagent (Invitrogen; Thermo Fisher Scientific, Inc.). RNA was reverse transcribed using PrimeScript RT reagent kit (Takara Bio, Inc., Otsu, Japan). qPCR was performed to detect mRNA expression using SYBR ${ }^{\circledR}$ Premix Ex Taq (Takara Bio, Inc.), with actin serving as an internal control. The cycling conditions for qRCR were as follows: $95^{\circ} \mathrm{C}$ for $30 \mathrm{sec} ; 40$ cycles of $95^{\circ} \mathrm{C}$ for $5 \mathrm{sec}$ and $60^{\circ} \mathrm{C}$ for $30 \mathrm{sec}$. TaqMan ${ }^{\circledR}$ microRNA assay (Applied Biosystems; Thermo Fisher Scientific, Inc.) was used to measure miRNA expression, with U6 serving as an internal control. The primer sequences used for qPCR were: miR-361, forward 5'-GATTCTTTCTTGGGACTCGGAAGCT-3' and reverse 5'-GGGATAAGATGCTAATGAATGTGCT-3'; U6 snRNA, forward 5'-CTCGCTTCGGCAGCACATATACT-3' and reverse 5'-ACGCTTCACGAATTTGCGTGTC-3'; WT1, forward 5'-GGGGTAAGGAGTTCAAGGCA-3' and reverse 5'-TGCAGCAAGAGGAAGTCCAG-3'; $\beta$-actin, forward 5'-CTCCATGGCCTCGCTGT-3' and reverse 5'-GCTGTC ACCTTCACCGTTCC-3'. All reactions were performed in triplicate. The relative expression levels were calculated using the $2^{-\Delta \Delta C \mathrm{q}}$ method (19).

Cell proliferation assay. Cell proliferation was evaluated using the MTT assay (Sigma-Aldrich; Merck Millipore, Darmstadt, Germany). In brief, 3,000 cells were seeded into each well of a 96-well plate. Following overnight incubation, cells were transfected with miR-361 mimic, NC miRNA, WT1 siRNA or siRNA ctrl. At various time points following transfection, MTT assays were conducted by adding $20 \mu \mathrm{l} 5 \mathrm{mg} / \mathrm{ml} \mathrm{MTT}$ assay reagent into each well and incubating plates at $37^{\circ} \mathrm{C}$ for $4 \mathrm{~h}$. The medium was carefully removed and $200 \mu \mathrm{l}$ dimethyl sulfoxide (Sigma-Aldrich; Merck Millipore) was added to solubilize the formazan precipitates. Optical density was measured at a wavelength of $490 \mathrm{~nm}$ using a spectrophotometer. Each sample was analyzed in triplicate.

Transwell assay. Transwell assays were performed to analyze cell migration and invasion abilities using transwell chambers with a pore size of $8-\mu \mathrm{m}$ (Corning Incorporated, Corning, NY, USA). For invasion assays, transwell chambers were coated with Matrigel (BD Biosciences, San Jose, CA, USA), according to the manufacturer's instructions. Cells were harvested $48 \mathrm{~h}$ following transfection and resuspended in culture medium without FBS. Transfected cells $\left(5 \times 10^{4}\right)$ in $200 \mu 1$ serum-free culture medium were seeded into the upper chamber of the transwell, and $500 \mu \mathrm{l}$ culture medium supplemented with $20 \%$ FBS was added into the lower chamber. Following a 24-h incubation, membranes were stained with $0.5 \%$ crystal violet (Beyotime Institute of Biotechnology, Nantong, China) for $20 \mathrm{~min}$. Cells that had not migrated or invaded to the basal side of the membranes were removed carefully with cotton wool. The protocol of migration assays was the same with invasion assay, but without Matrigel coating. The migration and invasion abilities were evaluated by counting five fields per membrane under an inverted microscope (Olympus Corporation, Tokyo, Japan). Each assay was repeated three times.

Western blotting. Total protein was extracted from cells using radioimmunoprecipitation assay buffer containing protease inhibitors (Thermo Fisher Scientific, Inc.). Equal quantities of proteins (20 $\mu \mathrm{g}$ per lane) were loaded onto $10 \%$ sodium dodecyl sulfate-polyacrylamide gel electrophoresis gels. Following electrophoresis, proteins were transferred to polyvinylidene difluoride membranes (EMD Millipore, Billerica, MA, USA). Membranes were blocked with 5\% non-fat milk powder in phosphate-buffered saline with $0.05 \%$ Tween 20 (PBST) at room temperature for $2 \mathrm{~h}$ and incubated with the primary antibodies: Mouse anti-human monoclonal WT1 antibody (1:500; catalog no. sc-7385; Santa Cruz Biotechnology, Inc., Dallas, TX, USA) and mouse anti-human monoclonal actin antibody (1:500; catalog no. sc-8432; Santa Cruz Biotechnology, Inc.). Following incubation at $4^{\circ} \mathrm{C}$ overnight, the membranes were washed three times with PBST, probed with goat anti-mouse HRP-conjugated secondary antibody (1:2,000 dilution; sc-2005; Santa Cruz Biotechnology, Inc.) at room temperature for $1 \mathrm{~h}$ and developed with Enhanced Chemiluminescence solution (Pierce Biotechnology, Inc., Rockford, IL, USA). Actin served as an internal control. The protein intensities were quantified using AlphaEase FC software (version 4.0.1; ProteinSimple, San Jose, CA, USA).

Dual-Luciferase reporter assay. HEK293T cells were seeded into 24 -well plates at a density of 30-40\% confluence. Cells were cotransfected with miR-361 mimic or NC and PGL3-WT1-3'UTR Wt or PGL3-WT1-3'UTR Mut using 
Lipofectamine 2000 when confluence reached 70-80\%. At $48 \mathrm{~h}$ following transfection, firefly and renilla luciferase activities were measured using a Dual-Luciferase ${ }^{\circledR}$ Reporter Assay system (Promega Corporation, Madison, WI, USA). Firefly luciferase activity served as an internal control. Each sample was analyzed in triplicate and the assay was repeated three times.

Statistical analysis. Data are presented as mean \pm standard deviation. All analyses were performed in SPSS software version 17.0 (SPSS, Inc., Chicago, IL, USA) using Student's t-test. $\mathrm{P}<0.05$ was considered to indicate a statistically significant difference.

\section{Results}

miR-361 is downregulated in NSCLC. In the present study, RT-qPCR was performed to measure the miR-361 expression levels in patients with NSCLC. miR-361 expression was significantly downregulated in NSCLC tissues compared with matched NATs $(\mathrm{P}=0.015$; Fig. $1 \mathrm{~A}$ and $\mathrm{B})$. In addition, the expression level of miR-361 was measured in NSCLC cell lines. Similar to the expression pattern in NSCLC samples, miR-361 expression levels were decreased in H23 and A549 NSCLC cell lines compared with the non-cancerous BEAS-2B cell line $(\mathrm{P}=0.020$ for $\mathrm{H} 23$ and $\mathrm{P}=0.004$ for $\mathrm{A} 549$; Fig. 1C).

miR-361 is upregulated in NSCLC cells following transfection with miR-361 mimics. To investigate the function of miR-361 in NSCLC, an miR-361 mimic or NC was transfected into H23 and A549 cells. Following transfection, RT-qPCR was performed to detect miR-361 expression. As presented in Fig. 2, miR-361 was significantly upregulated in H23 and A549 cells following transfection with an miR-361 mimic $(\mathrm{P}<0.001$ for $\mathrm{H} 23$ and $\mathrm{P}<0.001$ for $\mathrm{A} 549$ ).

miR-361 suppresses proliferation of NSCLC cells. To investigate the effect of miR-361 in the regulation of NSCLC cell growth, a proliferation assay was performed. Overexpression of miR-361 inhibited the proliferation of H23 and A549 cells compared with cells transfected with $\mathrm{NC}(\mathrm{P}<0.05$; Fig. 3$)$.

miR-361 suppresses migration and invasion of NSCLC cells. To investigate the potential effect of miR-361 on NSCLC metastasis, Transwell assays were performed. As presented in Fig. 4, miR-361 overexpression significantly suppressed the migration $(\mathrm{P}=0.026$ for $\mathrm{H} 23$ and $\mathrm{P}=0.022$ for $\mathrm{A} 549)$ and invasion ( $\mathrm{P}=0.028$ for $\mathrm{H} 23$ and $\mathrm{P}=0.035$ for $\mathrm{A} 549)$ of $\mathrm{H} 23$ and A549 cells compared with NC-transfected cells.

WT1 is a target of miR-361 in vitro. The online bioinformatics tools, TargetScan (www.targetscan.org/vert_71/) and miRanda (www.microrna.org/microrna/home.do) were used to identify the direct target of miR-361. Based on bioinformatic analysis, 239 potential targets were predicted. Among these putative targets, WT1 was selected for further investigation as it was upregulated and identified as an oncogene in lung cancer (20), with the predicted 3'UTR binding site presented in Fig. 5A. Dual-Luciferase reporter assays were performed to determine whether miR-361 directly targeted the 3'UTR of WT1.
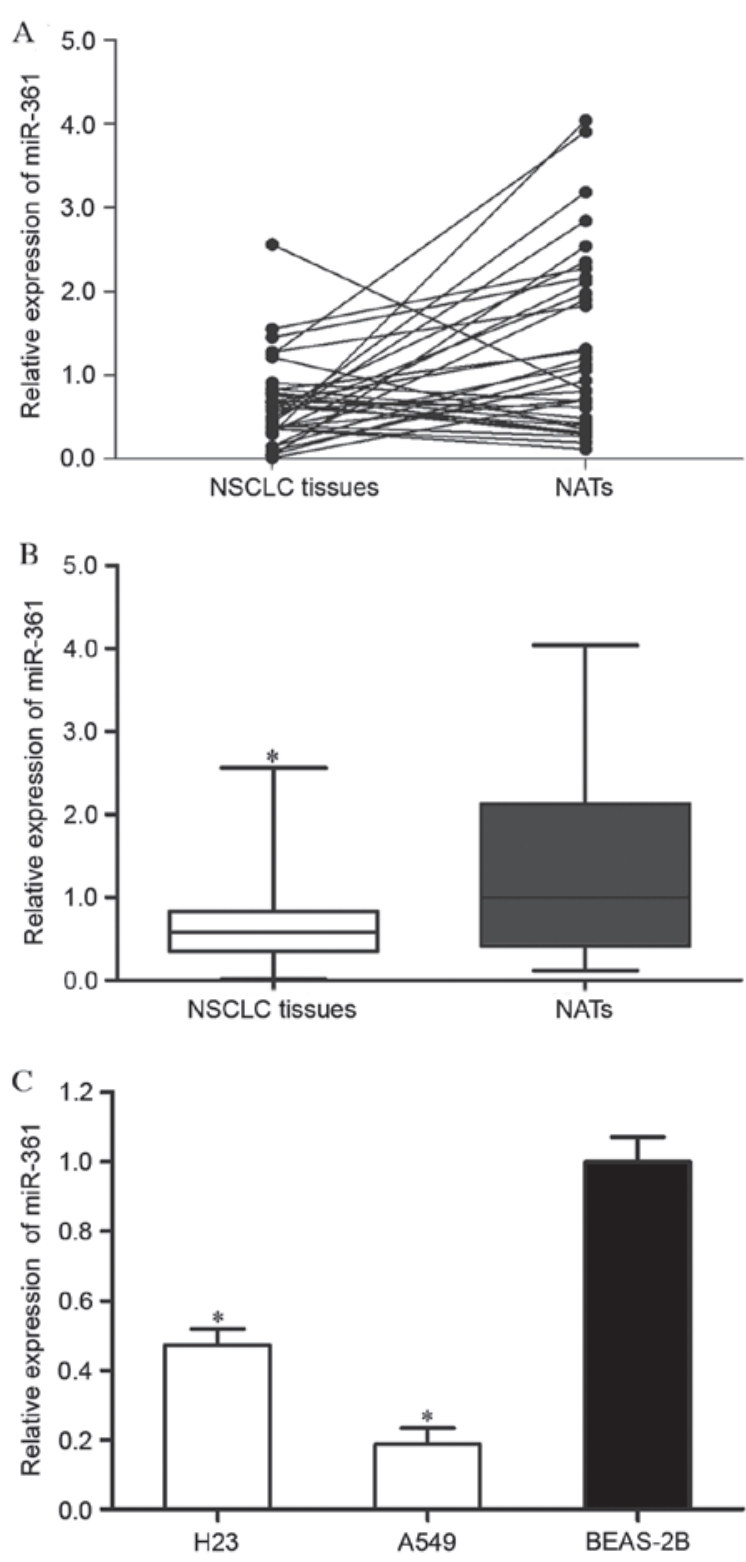

Figure 1. Downregulation of miR-361 in NSCLC tissues and cell lines. The expression level of miR-361 was assessed by reverse transcription-quantitative polymerase chain reaction in NSCLC tissues and matched NATs. This data is presented as (A) matched pairs and (B) the mean \pm standard deviation. miR-361 expression was significantly decreased in NSCLC tissues compared with NATs. (C) miR-361 expression levels were decreased in the H23 and A549 NSCLC cell lines compared with the non-tumorigenic BEAS-2B bronchial epithelial cell line. ${ }^{*} \mathrm{P}<0.05$ vs. NATs/BEAS-2B cells. miR, microRNA; NSCLC, non-small-cell lung cancer; NATs, normal adjacent tissues.

miR-361 decreased PGL3-WT1-3'UTR Wt luciferase activity in HEK293T cells compared with $\mathrm{NC}(\mathrm{P}=0.019$; Fig. 5B), but not PGL3-WT1-3'UTR Mut luciferase activity compared with $\mathrm{NC}(\mathrm{P}>0.05$; Fig. 5B). These findings suggested that WT1 is a direct target gene of miR-361.

miR-361 decreases WT1 expression in NSCLC cells. To further investigate whether WT1 was regulated by miR-361 in NSCLC cells, RT-qPCR and western blotting were performed. A total of $72 \mathrm{~h}$ following transfection, miR-361 overexpression decreased WT1 mRNA expression levels in H23 and A549 cells compared with NC-transfected cells $(\mathrm{P}=0.017$ for $\mathrm{H} 23$ 


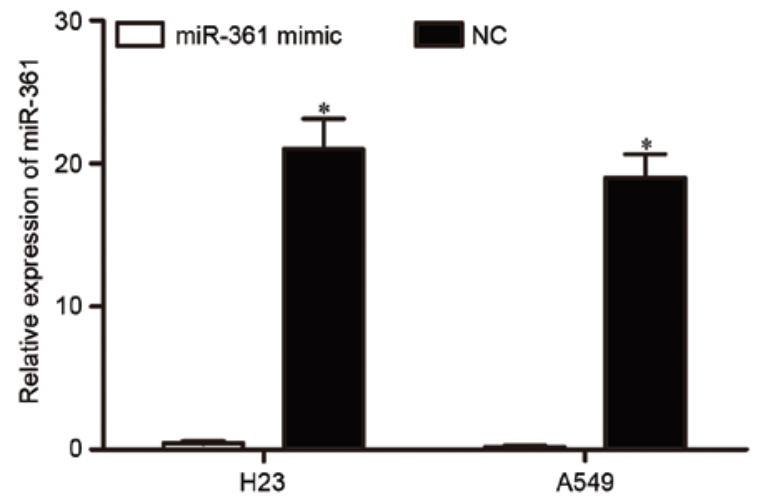

Figure 2. Overexpression of miR-361 in H23 and A549 cells. miR-361 expression levels were measured using reverse transcription-quantitative polymerase chain reaction $48 \mathrm{~h}$ following transfection of $\mathrm{H} 23$ and A549 cells with an miR-361 mimic or NC. Transfection with an miR-361 mimic increased the miR-361 expression levels in $\mathrm{H} 23$ and A549 cells compared with NC-transfected controls. "P $<0.05$ vs. NC. miR, microRNA; NC, negative control.
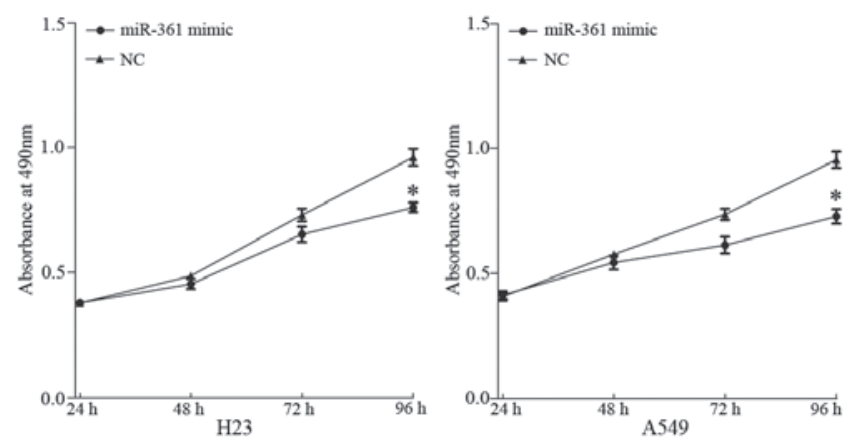

Figure 3. miR-361 suppresses proliferation of H23 and A549 cells. An MTT assay was performed to assess the effect of miR-361 overexpression on NSCLC cell growth. H23 and A549 cells transfected with an miR-361 mimic proliferated less than cells transfected with NC. ${ }^{*} \mathrm{P}<0.05$ vs. NC. miR, microRNA; NSCLC, non-small-cell lung cancer; NC, negative control.

and $\mathrm{P}=0.031$ for A549; Fig. 6A). Western blotting revealed that WT1 protein expression levels were downregulated by miR-361 overexpression in H23 and A549 cells, compared with NC-transfected controls $(\mathrm{P}=0.012$ for $\mathrm{H} 23$ and $\mathrm{P}=0.026$ for A549; Fig. 6B).

Knockdown of WT1 has similar effects to miR-361 overexpression in NSCLC cells. To investigate the functional effects of WT1 in NSCLC, WT1 or control siRNA was transfected into H23 and A549 cells. Following transfection, western blotting was performed to detect WT1 expression. As presented in Fig. 7A, WT1 was significantly downregulated in WT1 siRNA-transfected H23 and A549 cells compared with cells transfected with control siRNA ( $\mathrm{P}=0.034$ for $\mathrm{H} 23$ and $\mathrm{P}=0.018$ for A549).

Proliferation assays and Transwell assays revealed that knockdown of WT1 significantly suppressed the growth ( $\mathrm{P}=0.015$ for $\mathrm{H} 23$ and $\mathrm{P}=0.010$ for A549; Fig. 7B), migration ( $\mathrm{P}=0.039$ for $\mathrm{H} 23$ and $\mathrm{P}=0.024$ for A549; Fig. 7C) and invasion $(\mathrm{P}=0.019$ for $\mathrm{H} 23$ and $\mathrm{P}=0.023$ for $\mathrm{A} 549$; Fig. $7 \mathrm{C})$ of $\mathrm{H} 23$ and A549 cells $(\mathrm{P}<0.05)$. These findings demonstrated that the effects of WT1 siRNA were similar to the effects exerted by
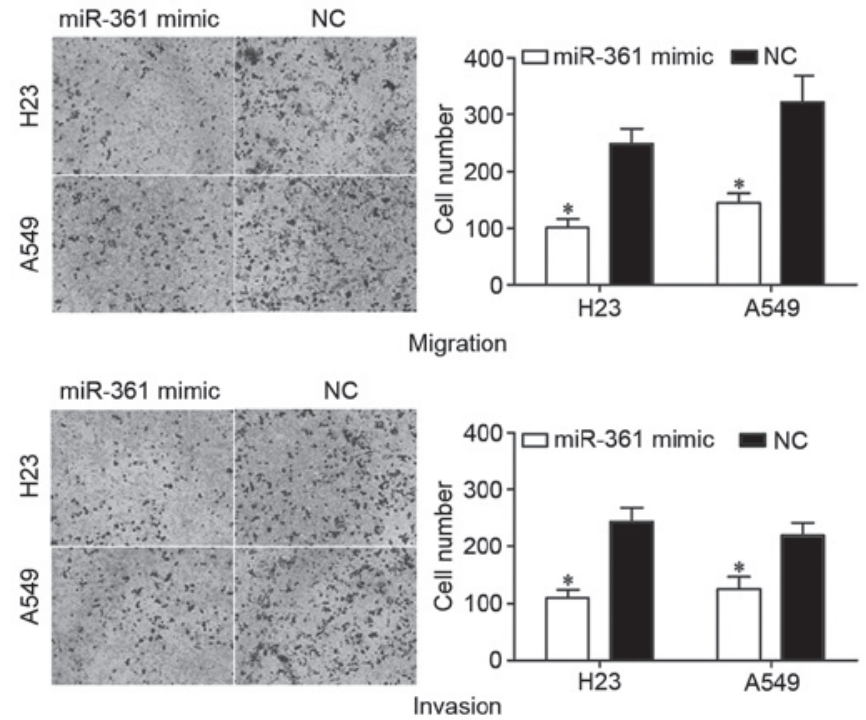

Figure 4. miR-361 suppresses migration and invasion of H23 and A549 cells. Transwell assays were performed to measure the effects of miR-361 overexpression on NSCLC cell migration and invasion. H23 and A549 cells transfected with miR-361 underwent decreased migration and invasion compared with cells transfected with NC. ${ }^{*} \mathrm{P}<0.05$ vs. NC. miR, microRNA; NSCLC, non-small-cell lung cancer; NC, negative control.

\section{A 5' CUGUGUAAAUAUAUGUCUGAUAA hsa-miR-361 WT1-3' UTR Mut 3' CAUGgGgaCCUCUAAGACUAUU 5 5' CUguguaAaUAUAUgAgACUAUA... 3'}

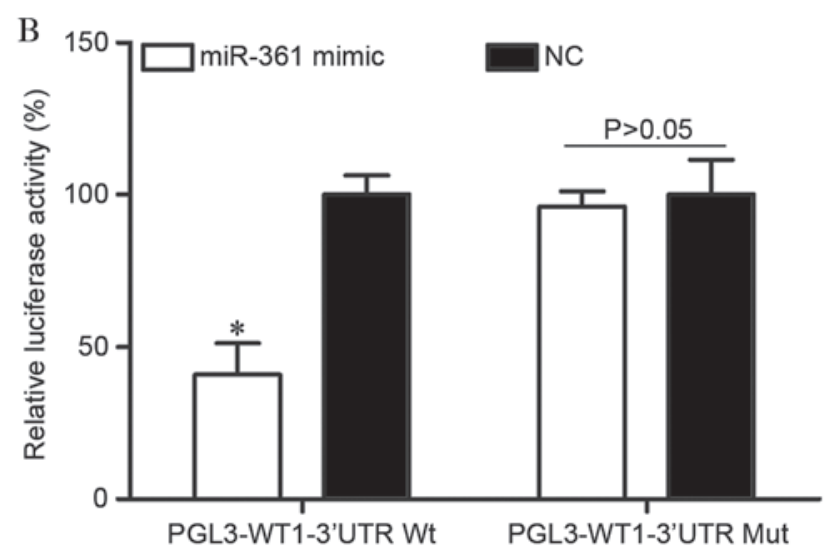

Figure 5. WT1 is a direct target of miR-361. (A) The potential miR-361 binding sequence in the WT1 3'UTR and the WT1 3'UTR sequence mutated at the binding site. (B) A dual-Luciferase reporter assay demonstrated that miR-361 overexpression decreased PGL3-WT1-3'UTR Wt, but not PGL3-WT1-3'UTR Mut, luciferase activity in HEK293T cells. * $\mathrm{P}<0.05$ vs. NC. miR, microRNA; WT1, Wilms' tumor 1; UTR, untranslated region; Wt, wild-type; Mut, mutant; NC, negative control.

miR-361 in NSCLC cells, indicating that WT1 is a functional target of miR-361 in NSCLC.

\section{Discussion}

Lung cancer is a malignant tumor that represents a serious challenge to human health. NSCLC accounts for $>85 \%$ of total lung cancer cases and has a poor prognosis (5). Therefore, it 

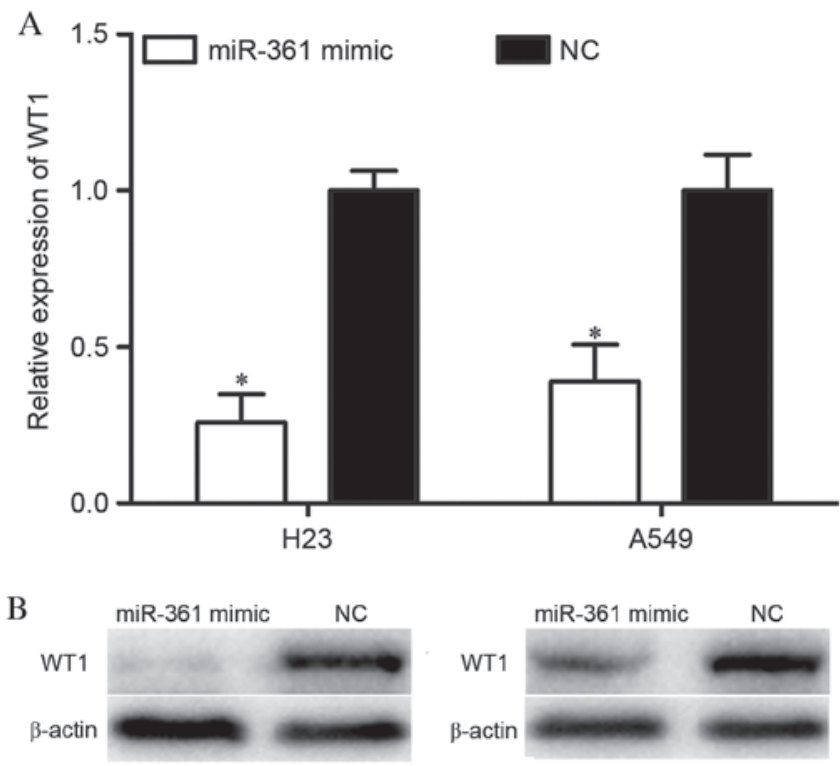

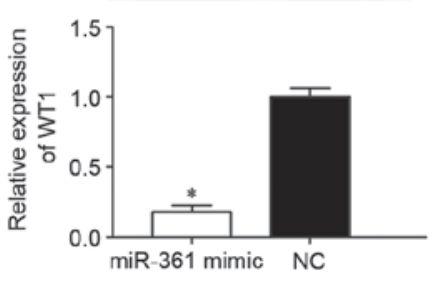

$\mathrm{H} 23$

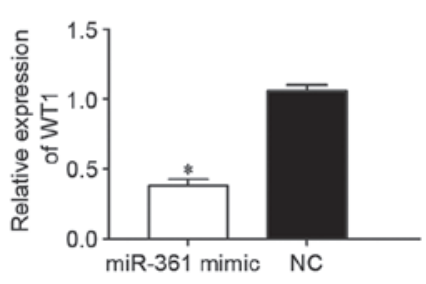

A549
Figure 6. miR-361 decreases WT1 expression in H23 and A549 cells. (A) Reverse transcription-quantitative polymerase chain reaction was performed $48 \mathrm{~h}$ following transfection to detect WT1 mRNA expression levels in H23 and A549 cells. (B) Western blotting was performed $72 \mathrm{~h}$ following transfection to measure WT1 protein expression levels in H23 and A549 cells. Overexpression of miR-361 decreased the mRNA and protein expression levels of WT1 in $\mathrm{H} 23$ and A549 cells. ${ }^{*} \mathrm{P}<0.05$ vs. NC. miR, microRNA; WT1, Wilms' tumor 1; NC, negative control.

is critical to understand the molecular mechanisms underlying NSCLC, and investigate novel therapeutic strategies for the treatment of this disease. It has been well documented that deregulated miRNA expression contributes to NSCLC carcinogenesis and progression $(21,22)$. Identification of tumor-associated miRNAs and the determination of their roles and target mRNAs is essential to develop novel therapeutic targets using this strategy (17). In the present study, it was demonstrated that miR-361 was downregulated in NSCLC tissues and cell lines. However, in a few patients, miR-361 was upregulated, which may be due to the tissue specificity of miR-361 expression. In addition, miR-361 significantly inhibited the proliferation, migration and invasion of NSCLC cells. Furthermore, WT1 was identified as a direct target of miR-361. These results suggested that miR-361 may function as a tumor suppressor in NSCLC and may be investigated as a potential therapy for the treatment of NSCLC.

miR-361 is located on Xq21.2, in an intron between exons 9 and 10 of the choroideremia gene (23). miR-361 is downregulated in numerous human cancers, including gastric cancer (24), colorectal cancer (24), prostate cancer (25) and cutaneous squamous cell carcinoma (23). In these cancers, miR-361 functions as a tumor suppressor. For example, in colorectal cancer, the expression level of miR-361 was negatively correlated with lung metastasis and disease progression. Furthermore,
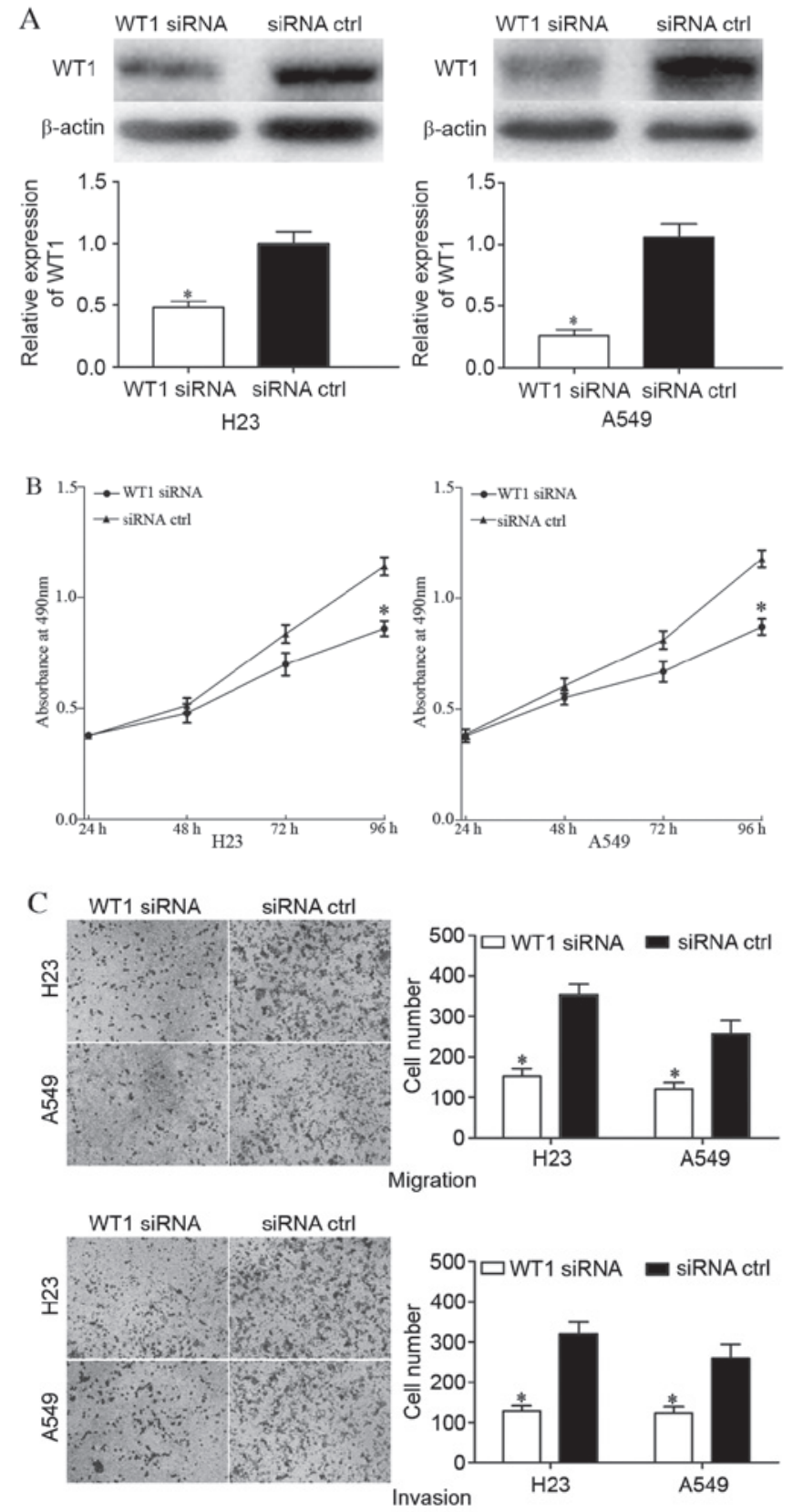

Figure 7. Knockdown of WT1 has similar effects to miR-361 overexpression in $\mathrm{H} 23$ and A549 cells. (A) Western blotting performed $72 \mathrm{~h}$ following transfection with WT1 or control siRNA revealed decreased WT1 protein expression levels in $\mathrm{H} 23$ and A549 cells transfected with WT1 siRNA. (B) Proliferation of H23 and A549 cells transfected with WT1 or control siRNA was assessed using an MTT assay; cell growth was suppressed by WT1 knockdown. (C) Transwell assays were used to investigate the migration and invasion of H23 and A549 cells transfected with WT1 or control siRNA; WT1 knockdown suppressed the migration and invasion of H23 and A549 cells compared with control siRNA-transfected cells. ${ }^{*} \mathrm{P}<0.05$ vs. siRNA ctrl. WT1, Wilms' tumor 1; miR, microRNA; siRNA, small interfering RNA; ctrl, control.

ectopic expression of miR-361 suppressed cell proliferation, migration and invasion via staphylococcal nuclease domain containing-1 (24). Liu et al (25) reported that miR-361 inhibited prostate cancer growth and enhanced apoptosis in vitro and in vivo by directly targeting the signal transducer and activator of transcription 6/B-cell lymphoma-extra large signaling pathway. However, in cervical cancer, miR-361 
has been reported to be upregulated, acting as an oncogene. Enforced miR-361 expression significantly increased cervical cancer cell growth, migration and invasion through mediation of epithelial-to-mesenchymal transition (26). These conflicting findings indicated that the expression and functions of miR-361 in tumors are diverse and tissue-specific.

Identification of miR-361 target mRNAs is important for understanding its role in NSCLC carcinogenesis and progression. In the present study, WT1 was identified as a direct target of miR-361 in NSCLC. Bioinformatics analysis revealed that WT1 mRNA contained a miR-361 seven-nucleotide seed match at positions 1,128-1,135 of the WT1 3'UTR. Dual-Luciferase reporter assays confirmed that miR-361 directly targeted the 3'UTR of WT1. In addition, RT-qPCR and western blotting demonstrated that miR-361 negatively regulated WT1 expression. Furthermore, knockdown of WT1 had similar effects to miR-361 overexpression in NSCLC cells. These results verified that miR-361 directly targeted WT1 to decrease NSCLC cell growth, migration and invasion. miR-361 may therefore be investigated as a potential targeted therapy to inhibit the rapid growth and metastasis of NSCLC.

WT1, located on chromosome 11p13, was first identified in 1990 in the childhood kidney cancer Wilms' tumor (27). It encodes a zinc-finger transcription factor consisting of four zinc finger domains at the $\mathrm{C}$ terminus and a glutamine and proline-rich domain at the $\mathrm{N}$ terminus $(28,29)$. Previous studies have revealed that WT1 is upregulated in a large number of human cancers, including breast cancer, ovarian cancer, glioblastoma and soft tissue sarcoma (30-33). In functional studies, WT1 was demonstrated to be a tumor suppressor, which is inactivated in Wilms' tumor (27). However, studies have identified WT1 as an oncogene in other human tumors (34-37). For example, in ovarian cancer, high WT1 expression was correlated with the stage of the disease, ascites production and metastasis. In addition, WT1 promoted ovarian cancer invasion $(38,39)$. In breast cancer, WT1 expression level was associated with basal-like and receptor tyrosine-protein kinase erbB-2 molecular subtypes and poor prognosis (40). In addition, it was demonstrated to enhance growth and inhibit apoptosis of breast cancer cells $(41,42)$. Furthermore, WT1 promoted migration, metastasis and angiogenesis, and induced drug resistance of cancer cells (43).

In NSCLC, WT1 was upregulated in cancer specimens compared with NATs (44). Functional studies revealed that WT1 enhanced cell proliferation, invasion, cisplatin-resistance and decreased apoptosis (44-47). The present study, in accordance with previous findings, demonstrated that knockdown of WT1 inhibited growth, migration and invasion of NSCLC cells. These findings indicated that it may be beneficial to investigate novel therapies targeting WT1. miR-361 may be investigated as a potential therapy to target WT1 and therefore inhibit the rapid growth and metastasis of NSCLC.

In conclusion, the results of the present study revealed that miR-361 was downregulated in NSCLC tissues and cell lines. Ectopic expression of miR-361 suppressed the proliferation, migration and invasion of NSCLC cells via the direct targeting of WT1. The present study provided novel insights into the molecular mechanism underlying the rapid growth and metastasis of NSCLC, and identified the association between
miR-361 and WT1 as a potential therapeutic target for the treatment of NSCLC.

\section{References}

1. Ilic N, Petricevic A, Arar D, Kotarac S, Banovic J, Ilic NF, Tripkovic A and Grandic L: Skip mediastinal nodal metastases in the IIIa/N2 non-small cell lung cancer. J Thorac Oncol 2: 1018-1021, 2007.

2. Siegel R, Ma J, Zou Z and Jemal A: Cancer statistics, 2014. CA Cancer J Clin 64: 9-29, 2014.

3. Siegel RL, Miller KD and Jemal A: Cancer statistics, 2015. CA Cancer J Clin 65: 5-29, 2015.

4. Ni T, Mao G, Xue Q, Liu Y, Chen B, Cui X, Lv L, Jia L, Wang Y and Ji L: Upregulated expression of ILF2 in non-small cell lung cancer is associated with tumor cell proliferation and poor prognosis. J Mol Histol 46: 325-335, 2015.

5. Chen X, Liu Y, Røe OD, Qian Y, Guo R, Zhu L, Yin Y and Shu Y: Gefitinib or erlotinib as maintenance therapy in patients with advanced stage non-small cell lung cancer: A systematic review. PLoS One 8: e59314, 2013.

6. Wang F, Zhou J, Zhang Y, Wang Y, Cheng L, Bai Y and Ma H: The value of microRNA-155 as a prognostic factor for survival in non-small cell lung cancer: A meta-analysis. PLoS One 10: e0136889, 2015.

7. Verdecchia A, Francisci S, Brenner H, Gatta G, Micheli A, Mangone L and Kunkler I; EUROCARE-4 Working Group: Recent cancer survival in Europe: A 2000-02 period analysis of EUROCARE-4 data. Lancet Oncol 8: 784-796, 2007.

8. Sakashita S, Sakashita M and Sound Tsao M: Genes and pathology of non-small cell lung carcinoma. Semin Oncol 41: 28-39, 2014.

9. Wei J, MaZ, Li Y,Zhao B, Wang D, Jin Y and Jin Y: miR-143 inhibits cell proliferation by targeting autophagy-related $2 \mathrm{~B}$ in non-small cell lung cancer H1299 cells. Mol Med Rep 11: 571-576, 2015.

10. Wu D, Pan H, Zhou Y, Zhang Z, Qu P, Zhou J and Wang W: Upregulation of microRNA-204 inhibits cell proliferation, migration and invasion in human renal cell carcinoma cells by downregulating SOX4. Mol Med Rep 12: 7059-7064, 2015.

11. Tao J, Wu D, Xu B, Qian W, Li P, Lu Q, Yin C and Zhang W: microRNA-133 inhibits cell proliferation, migration and invasion in prostate cancer cells by targeting the epidermal growth factor receptor. Oncol Rep 27: 1967-1975, 2012.

12. Ebrahimi A and Sadroddiny E: MicroRNAs in lung diseases: Recent findings and their pathophysiological implications. Pulm Pharmacol Ther 34: 55-63, 2015.

13. Li X, Abdel-Mageed AB, Mondal D and Kandil E: MicroRNA expression profiles in differentiated thyroid cancer, a review. Int J Clin Exp Med 6: 74-80, 2013.

14. Bartel DP: MicroRNAs: Genomics, biogenesis, mechanism, and function. Cell 116: 281-297, 2004.

15. Carthew RW and Sontheimer EJ: Origins and mechanisms of miRNAs and siRNAs. Cell 136: 642-655, 2009.

16. Esquela-Kerscher A and Slack FJ: Oncomirs-microRNAs with a role in cancer. Nat Rev Cancer 6: 259-269, 2006.

17. Lu J, Getz G, Miska EA, Alvarez-Saavedra E, Lamb J, Peck D, Sweet-Cordero A, Ebert BL, Mak RH, Ferrando AA, et al: MicroRNA expression profiles classify human cancers. Nature 435: 834-838, 2005.

18. Volinia S, Calin GA, Liu CG, Ambs S, Cimmino A, Petrocca F, Visone R, Iorio M, Roldo C, Ferracin M, et al: A microRNA expression signature of human solid tumors defines cancer gene targets. Proc Natl Acad Sci USA 103: 2257-2261, 2006.

19. Livak KJ and Schmittgen TD: Analysis of relative gene expression data using real-time quantitative PCR and the 2(-Delta Delta C (T)) Method. Methods 25: 402-408, 2001.

20. Wang X, Gao P, Lin F, Long M, Weng Y, Ouyang Y, Liu L, Wei J, Chen X, He T, et al: Wilms' tumour suppressor gene 1 (WT1) is involved in the carcinogenesis of lung cancer through interaction with PI3K/Akt pathway. Cancer Cell Int 13: 114, 2013.

21. Ma Q, Jiang Q, Pu Q, Zhang X, Yang W, Wang Y, Ye S, Wu S, Zhong G, Ren J, et al: MicroRNA-143 inhibits migration and invasion of human non-small-cell lung cancer and its relative mechanism. Int J Biol Sci 9: 680-692, 2013.

22. Zhang Y, Yang X, Wu H, Zhou W and Liu Z: MicroRNA-145 inhibits migration and invasion via inhibition of fascin 1 protein expression in non-small-cell lung cancer cells. Mol Med Rep 12: 6193-6198, 2015. 
23. Kanitz A, Imig J, Dziunycz PJ, Primorac A, Galgano A, Hofbauer GF, Gerber AP and Detmar M: The expression levels of microRNA-361-5p and its target VEGFA are inversely correlated in human cutaneous squamous cell carcinoma. PLoS One 7: e49568, 2012.

24. Ma F, Song H, Guo B, Zhang Y, Zheng Y, Lin C, Wu Y, Guan G, Sha R, Zhou Q, et al: MiR-361-5p inhibits colorectal and gastric cancer growth and metastasis by targeting staphylococcal nuclease domain containing-1. Oncotarget 6: 17404-17416, 2015.

25. Liu D, Tao T, Xu B, Chen S, Liu C, Zhang L, Lu K, Huang Y, Jiang L, Zhang X, et al: MiR-361-5p acts as a tumor suppressor in prostate cancer by targeting signal transducer and activator of transcription-6 (STAT6). Biochem Biophys Res Commun 445: 151-156, 2014.

26. Wu X, Xi X, Yan Q, Zhang Z, Cai B, Lu W and Wan X: MicroRNA-361-5p facilitates cervical cancer progression through mediation of epithelial-to-mesenchymal transition. Med Oncol 30: 751, 2013.

27. Call KM, Glaser T, Ito CY, Buckler AJ, Pelletier J, Haber DA, Rose EA, Kral A, Yeger H, Lewis WH, et al: Isolation and characterization of a zinc finger polypeptide gene at the human chromosome 11 Wilms' tumor locus. Cell 60: 509-520, 1990.

28. Gessler M, Poustka A, Cavenee W, Neve RL, Orkin SH and Bruns GA: Homozygous deletion in Wilms tumours of a zinc-finger gene identified by chromosome jumping. Nature 343 : 774-778, 1990.

29. Hohenstein P and Hastie ND: The many facets of the Wilms tumour gene, WT1. Hum Mol Genet 15: R196-R201, 2006.

30. Oji Y, Ogawa H, Tamaki H, Oka Y, Tsuboi A, Kim EH, Soma T, Tatekawa T, Kawakami M, Asada M, et al: Expression of the Wilms' tumor gene WT1 in solid tumors and its involvement in tumor cell growth. Jpn J Cancer Res 90: 194-204, 1999.

31. Menssen HD, Bertelmann E, Bartelt S, Schmidt RA, Pecher G, Schramm K and Thiel E: Wilms' tumor gene (WT1) expression in lung cancer, colon cancer and glioblastoma cell lines compared to freshly isolated tumor specimens. J Cancer Res Clin Oncol 126: 226-232, 2000.

32. Nakatsuka S, Oji Y, Horiuchi T, Kanda T, Kitagawa M, Takeuchi T, Kawano K, Kuwae Y, Yamauchi A, Okumura M, et al: Immunohistochemical detection of WT1 protein in a variety of cancer cells. Mod Pathol 19: 804-814, 2006.

33. Miyoshi Y, Ando A, Egawa C, Taguchi T, Tamaki Y, Tamaki H, Sugiyama $\mathrm{H}$ and Noguchi S: High expression of Wilms' tumor suppressor gene predicts poor prognosis in breast cancer patients Clin Cancer Res 8: 1167-1171, 2002.

34. Mayo MW, Wang CY, Drouin SS, Madrid LV, Marshall AF, Reed JC, Weissman BE and Baldwin AS: WT1 modulates apoptosis by transcriptionally upregulating the bcl-2 proto-oncogene. EMBO J 18: 3990-4003, 1999.
35. Richard DJ, Schumacher V, Royer-Pokora B and Roberts SG: Par4 is a coactivator for a splice isoform-specific transcriptional activation domain in WT1. Genes Dev 15: 328-339, 2001

36. Ito K, Oji Y, Tatsumi N, Shimizu S, Kanai Y, Nakazawa T, Asada M, Jomgeow T, Aoyagi S, Nakano Y, et al: Antiapoptotic function of 17AA(+)WT1 (Wilms' tumor gene) isoforms on the intrinsic apoptosis pathway. Oncogene 25: 4217-4229, 2006

37. Tatsumi N, Oji Y, Tsuji N, Tsuda A, Higashio M, Aoyagi S, Fukuda I, Ito K, Nakamura J, Takashima S, et al: Wilms' tumor gene WT1-shRNA as a potent apoptosis-inducing agent for solid tumors. Int J Oncol 32: 701-711, 2008.

38. Barbolina MV, Adley BP, Shea LD and Stack MS: Wilms tumor gene protein 1 is associated with ovarian cancer metastasis and modulates cell invasion. Cancer 112: 1632-1641, 2008.

39. Liu Z, Yamanouchi K, Ohtao T, Matsumura S, Seino M, Shridhar V, Takahashi T, Takahashi K and Kurachi H: High levels of Wilms' tumor 1 (WT1) expression were associated with aggressive clinical features in ovarian cancer. Anticancer Res 34: 2331-2340, 2014

40. Qi XW, Zhang F, Yang XH, Fan LJ, Zhang Y, Liang Y, Ren L, Zhong L, Chen QQ, Zhang KY, et al: High Wilms' tumor 1 mRNA expression correlates with basal-like and ERBB2 molecular subtypes and poor prognosis of breast cancer. Oncol Rep 28: 1231-1236, 2012.

41. Zapata-Benavides P, Tuna M, Lopez-Berestein G and Tari AM: Downregulation of Wilms' tumor 1 protein inhibits breast cancer proliferation. Biochem Biophys Res Commun 295: 784-790, 2002.

42. Tuna M, Chavez-Reyes A and Tari AM: HER2/neu increases the expression of Wilms' Tumor 1 (WT1) protein to stimulate S-phase proliferation and inhibit apoptosis in breast cancer cells. Oncogene 24: 1648-1652, 2005.

43. Qi XW, Zhang F, Wu H, Liu JL, Zong BG, Xu C and Jiang J: Wilms' tumor 1 (WT1) expression and prognosis in solid cancer patients: A systematic review and meta-analysis. Sci Rep 5: 8924, 2015.

44. Xu C, Wu C, Xia Y, Zhong Z, Liu X, Xu J, Cui F, Chen B, Røe OD, Li A and Chen Y: WT1 promotes cell proliferation in non-small cell lung cancer cell lines through up-regulating cyclin D1 and p-pRb in vitro and in vivo. PLoS One 8: e68837, 2013.

45. Wu C, Wang S, Xu C, Tyler A, Li X, Andersson C, Oji Y Sugiyama H, Chen Y and Li A: WT1 enhances proliferation and impedes apoptosis in KRAS mutant NSCLC via targeting cMyc. Cell Physiol Biochem 35: 647-662, 2015.

46. Wu C, Wang Y, Xia Y, He S, Wang Z, Chen Y, Wu C, Shu Y and Jiang J: Wilms' tumor 1 enhances Cisplatin-resistance of advanced NSCLC. FEBS Lett 588: 4566-4572, 2014.

47. Wu C, Zhu W, Qian J, He S, Wu C, Chen Y and Shu Y: WT1 promotes invasion of NSCLC via suppression of CDH1. J Thorac Oncol 8: 1163-1169, 2013. 